\title{
Impact of central complex lesions on visual orientation in ants: Turning behaviour, but not the overall movement direction, is disrupted
}

Scarlett Dell-Cronin ${ }^{13}$, Cornelia Buehlmann ${ }^{13^{*}}$, Angela Diyalagoda Pathirannahelage ${ }^{1}$, Roman Goulard $^{2}$, Barbara Webb ${ }^{2}$, Jeremy Niven ${ }^{1} \&$ Paul Graham ${ }^{1}$ ${ }^{1}$ School of Life Sciences, University of Sussex, Brighton, BN1 9QG, UK ${ }^{2}$ School of Informatics, University of Edinburgh, Edinburgh, EH8 9AB, UK

${ }^{3}$ Joint first author

*Corresponding author

\begin{abstract}
Wood ants are excellent navigators using a combination of innate and learnt navigational strategies to travel between their nest and feeding sites. Visual navigation in ants has been studied extensively, however, we only know little about the underlying neural mechanisms. The central complex $(\mathrm{CX})$ is located at the midline of the insect brain. It receives sensory input that allows an insect to keep track of the direction of sensory cues relative to its own orientation and to control movement. We show here direct evidence for the involvement of the central complex in the innate visual orientation response of freely moving wood ants. Lesions in the CX disrupted the control of turning in a lateralised manner, but had no effect on the overall heading direction, walking speed or path straightness.
\end{abstract}

\section{KEYWORDS}

Central Complex, innate visual behaviour, visual orientation, wood ants, Formica rufa

\section{INTRODUCTION}

Ant foragers travel diligently back and forth between their nest and feeding sites using a combination of innate and learnt navigational strategies (Knaden \& Graham 2016; Buehlmann et al. 2020b). Innate strategies such as path integration (e.g. (Collett et al. 2001; Mueller \& Wehner 2010)), pheromone trails (e.g. (Harrison et al. 1989)), attraction to food odours (Buehlmann et al. 2014), and/or attraction to visual cues (e.g. (Graham et al. 2003; Collett 2010)) are vital for ants that are unfamiliar in an environment. Wood ants show an innate attraction to large conspicuous objects which can form 
part of their navigational repertoire (Voss 1967; Graham et al. 2003; Buehlmann et al. 2020a;

Buehlmann et al. 2020c; Buehlmann \& Graham 2021). This innate behaviour can form the basis for learnt foraging routes (Graham et al. 2003). Visual navigation in ants has been studied extensively (Zeil 2012; Collett et al. 2013; Wehner et al. 2014; Graham \& Philippides 2017), however, knowledge about the underlying neural mechanisms lags behind (Webb \& Wystrach 2016; Heinze 2017).

The central complex (CX), a collection of neuropils located at the midline of the insect brain (Strausfeld 1999), receives sensory input allowing an insect to keep track of the direction of sensory cues relative to its own orientation (Seelig \& Jayaraman 2015), and to directly control movement (Martin et al. 2015). A few studies have shown that the CX plays a role in insects that navigate using celestial information (e.g. locusts: (Vitzthum et al. 2002; Pegel et al. 2018); dung beetles: (el Jundi et al. 2015); monarch butterfly: (Heinze \& Reppert 2011; Heinze et al. 2013); bees: (Stone et al. 2017); crickets: (Sakura et al. 2008)) or terrestrial visual information (fruit flies: (Liu et al. 2006; Neuser et al. 2008; Ofstad et al. 2011; Kuntz et al. 2012; Seelig \& Jayaraman 2013); cockroaches: (Ritzmann et al. 2008); locust: (Rosner \& Homberg 2013)). In these insects, the CX has a role in the control of speed, turning behaviour, and spatial orientation (reviewed in (Pfeiffer \& Homberg 2014; Varga et al. 2017; Honkanen et al. 2019)). Furthermore, an increase of the CX volume was shown in new ant foragers that were exposed to skylight information during the learning of navigationally relevant information at the offset of their foraging career, indicating its involvement in navigation (Grob et al. 2017).

We show here direct evidence for the involvement of the $\mathrm{CX}$ in the innate visual orientation response of freely moving wood ants. Lesions in the CX disrupted the control of turning in a lateralised manner, but had no effect on the overall heading direction, walking speed or path straightness.

\section{METHODS}

\section{Ants}

Experiments were performed with laboratory kept wood ants Formica rufa L. collected from Ashdown forest, East Sussex, UK. Ants were kept in the laboratory under a $12 \mathrm{~h}$ light: $12 \mathrm{~h}$ darkness cycle at $25-27^{\circ} \mathrm{C}$. Ants were fed ad libitum with sucrose, dead crickets and water. During the experiments, food was limited to a minimum to increase the ants' foraging motivation, but water was permanently available.

\section{Lesion procedures}

Ants were immobilised on ice for 90 seconds and harnessed in a custom-made holder keeping their head fixed with plasticine while their body was free to move. Antennae were restrained with a pin. To access the CX, a small window was cut with a piece of razor blade below the medial ocellus. 
Mechanical lesions were made relative to landmarks (including tracheal branches) visible on the anterior surface of the brain. The bottom of the central tracheal branch (Figure 1A), directly below the medial ocellus, indicated the position of the CX (Figure 1B). Glass capillaries (Harvard Apparatus, Cambourne, UK; 30-0035; $1.00 \mathrm{~mm}$ outer diameter, $0.78 \mathrm{~mm}$ inner diameter, $10 \mathrm{~mm}$ length) were pulled with a P-97 Micropipette Puller (Sutter Instrument, Novato, California, USA) and then broken manually to a tip size of $10 \mu \mathrm{m}$ and dipped in black ink to aid visibility. After inserting the capillary into either the left or right side of the CX (Figure 1A), the cuticle lid was replaced and secured in place with a small drop of cyanoacrylate adhesive. Control ants were handled and dissected in the same way as lesion ants except for the actual lesion.

\section{Experimental setup}

After resting for 10 minutes, ants were released in the centre of a circular platform $(120 \mathrm{~cm}$ in diameter) within a cylindrical arena (diameter $3 \mathrm{~m}$, height $1.8 \mathrm{~m}$ ) with white walls (Figure 1C). A $20^{\circ}$ wide rectangle (height: $90 \mathrm{~cm}$, width: $52 \mathrm{~cm}$ ) was placed on the inner wall of the surrounding cylinder. To remove possible olfactory cues, the surface of the platform was covered with white paper, which was rotated between recordings. The centre of the platform consisted of a cylindrical release chamber of $6.5 \mathrm{~cm}$ diameter, which was remotely lowered to release the ant onto the platform. The ants' position and body orientation were recorded every $20 \mathrm{~ms}$ using a tracking video camera (Trackit, SciTrackS $\mathrm{GmbH})$ and trajectories were analysed in Matlab.

\section{RESULTS}

\section{Walking speed and overall path straightness are not affected by CX lesions}

CX lesions affected the ants' propensity to move. 12 out of 80 CX-lesioned ants did not leave the release chamber $(r=3.25 \mathrm{~cm})$, whereas only 1 out of 55 control ants, which had all the handling including head opening but no lesion, did not reach $r=3.25 \mathrm{~cm}$ (Chi-square test, $p<0.05$ ). Walking speed and general path straightness of those ants that left the release chamber were not affected by the lesions (Control, $\mathrm{n}=54$ ants; CX lesions, $\mathrm{n}=68$ ants; Mann Whitney test; walking speed, $\mathrm{p}>0.05$; path straightness, $p>0.05$ ). Hence, although initial tendency to move was lower in lesioned ants, $C X$ lesions had no impact on walking speed or overall path straightness in ants that left the release chamber. However, even though there was no difference in overall path straightness, lesioned ants produced a significantly higher number of loops, i.e. path segments where an ant turned around and re-crossed its own path, than the control ants (Control, median, 4 loops/m; Lesions, median, 9 loops/m; Mann Whitney test, $\mathrm{p}<0.05)$.

\section{Innate visual orientation of CX lesioned ants is not impaired}



$2 \mathrm{~A}, \mathrm{n}=54$ ants) and lesioned ants from both groups (Figure 2B, left lesions, LLes, $\mathrm{n}=35$ ants; Figure $2 \mathrm{C}$, right lesion, RLes, $\mathrm{n}=33$ ants) were directed (Rayleigh test, all $\mathrm{p}<0.001$ ). Ants from the three groups did not differ from each other (Watson Williams tests, all $\mathrm{p}>0.05$ ) and they all approached the visual cue, i.e. the $95 \%$ CI of the ants' final heading direction encompassed the visual cue (Figure 2).

\section{CX lesions disrupt turning}

Detailed path analysis from ants that approached the centre of the visual cue $+/-90^{\circ}$ revealed that control ants as expected spent on average an equal amount of time turning to the left and right (Contr, $\mathrm{n}=42$ ants; Wilcoxon test, $\mathrm{p}>0.05$ ), whereas the average length of left and right turns in both lesion groups was significantly different (LLes, $\mathrm{n}=29$ ants; RLes, $\mathrm{n}=27$ ants; Wilcoxon test, both $\mathrm{p}<$ 0.001 ). Lesioned ants spent less time turning to the ipsilateral side of the lesion, i.e. ants lesioned on the right spent less time turning to the right and vice versa (Figure 3A). Analysis of the magnitude of these turns revealed that there was no difference between left and right turns in all three groups (Figure 3B; Wilcoxon tests; Contr, $\mathrm{n}=42$ ants; LLes, $\mathrm{n}=28$ ants; RLes, $\mathrm{n}=27$ ants; all $\mathrm{p}>0.05$ ). The angles at the end of the turns differed in all three groups between left and right turns (Figure 3C). At the end of a right turn, ants looked to the right relative to the centre of the visual cue, whereas at the end of a left turn, ants looked to the left of the centre of the visual cue (Wilcoxon tests; Contr, $n=42$ ants, $p<0.001$; LLes, $\mathrm{n}=28$ ants, $\mathrm{p}<0.01$; RLes, $\mathrm{n}=27$ ants, $\mathrm{p}<0.001$ ). The end points after both the left and right turns respectively did not differ between the three groups (Watson Williams tests, all $\mathrm{p}>0.05$ ).

\section{DISCUSSION}

In recent years the $\mathrm{CX}$ has received attention as a brain area crucial for orientation in insects (Pfeiffer \& Homberg 2014; Turner-Evans \& Jayaraman 2016; Varga et al. 2017; Honkanen et al. 2019). The CX receives pre-processed sensory input that allows insects to orient themselves relative to external cues (Seelig \& Jayaraman 2015). Furthermore, the CX can directly control movement (Bender et al. 2010). We show here that lesions in the $C X$ lead to a lateralised disruption in ants' turning behaviour (Figure 3) but that ants with lateralised CX lesions can still control their overall orientation relative to a visual cue (Figure 2). Below we consider two, non-mutually exclusive, impacts that our lesion might have had on the sensorimotor circuitry of the ants.

\section{Control of innate visual behaviour in the $\mathrm{CX}$}

Many insects show sensori-motor reflex behaviours, i.e. they perform particular motor behaviours in response to specific visual stimuli. Long vertical objects are attractive for many insects, including ants (fruit flies: (Wehner 1972; Gotz 1987; Strauss \& Pichler 1998), locusts: (Wallace 1962), ladybirds: (Collett 1988), mantids: (Poteser \& Kral 1995), ants: (Voss 1967; Heusser \& Wehner 2002; 
Graham et al. 2003; Collett 2010; Buehlmann et al. 2020a; Buehlmann et al. 2020c; Buehlmann \& Graham 2021)). Experiments in Drosophila have revealed that the CX is required for the flies' innate visual responses (Bausenwein et al. 1994) and spatial learning paradigms in Drosophila revealed its importance for visual and spatial memory and directional decision making (Neuser et al. 2008; Ofstad et al. 2011; Kuntz et al. 2012; Seelig \& Jayaraman 2013; Seelig \& Jayaraman 2015). Neurons in the ellipsoid body map visual cues spatially (Seelig \& Jayaraman 2013) and the lateralised ellipsoid body input in Drosophila, has been shown to be suitable for innate responses to bars (Dewar et al. 2017). In addition, ellipsoid body neurones have been shown to be important for short-term spatial memory, during which they encode the position of a target (e.g. an attractive visual cue) and can guide movement towards it (Neuser et al. 2008) even when temporarily invisible. Given the conservation of function in the CX across insects, it is likely that the ellipsoid body does play a similar role in ants. With lateralised lesions ants retained their innate attraction to the visual cue, albeit with lateralised disruption because the very wide field visual inputs from each visual hemisphere (Seelig \& Jayaraman 2013; Dewar et al. 2017) are sufficient for overall path control, suggesting some redundancy in the visual inputs used for innate visual attraction.

\section{Control of turning behaviour by the $\mathrm{CX}$}

The CX is also involved in fine-scale control of steering including the control of walking speed (Bender et al. 2010; Martin et al. 2015) and turning (Guo \& Ritzmann 2013). The symmetrical features of the CX along the medial-lateral axis might suggest a lateralized role of the CX (see e.g. (Pfeiffer \& Homberg 2014). We show here that lesioned ants spent less time turning to the ipsilateral side of the lesion, i.e. right lesion ants spent less time turning to the right whereas left lesion ants spent less time turning to the left (Figure 3A). Ridgel and co-workers showed in cockroaches that off-centre CX lesions resulted in lateralised navigational deficits (Ridgel et al. 2007). More specifically, lesioned cockroaches lost the ability to turn in the ipsilateral direction relative to the lesion (Ridgel et al. 2007; Guo \& Ritzmann 2013). Furthermore, CX stimulations experiments showed evoked turning to the ipsilateral side, i.e. stimulating the left CX evoked left turns and vice versa (Guo \& Ritzmann 2013; Martin et al. 2015). Hence, the CX controls steering in a lateralized way, in both cockroaches and ants.

It has previously been suggested that visual control of orientation in wood ants involves 'correction points' that are synchronised with the underlying path 'wiggle' or sinuosity (Lent et al. 2010; Collett et al. 2014). This suggest that there may be some independence between the control of underlying path sinuosity (perhaps from the lateral accessory lobes; (Steinbeck et al. 2020)) and of visual corrections. Lateralised lesions in ants might not therefore knock-out the control of all turns in one direction but might diminish the visual control of those turns. However, redundancy in the visual inputs that allow for innate visual orientation, mean that ants' overall paths are still directed to the visual cue. 


\section{ACKNOWLEDGEMENTS}
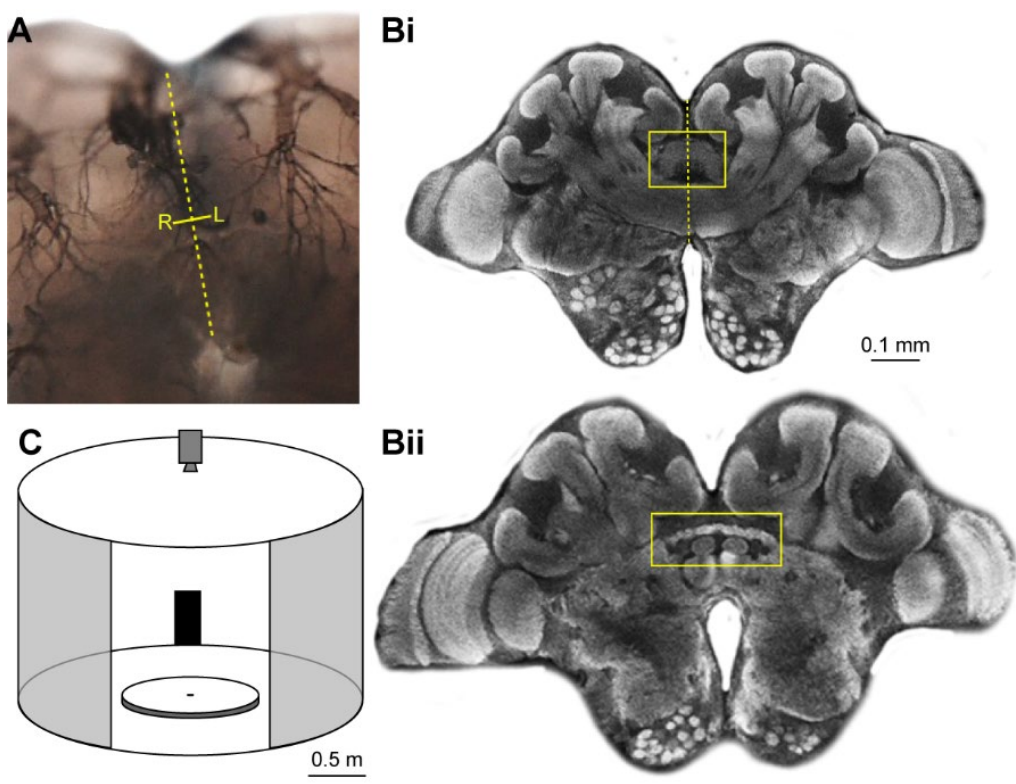

\section{Figure 1}

172

Figure 1: CX lesion locations and experimental setup. (A) Mechanical lesions were made relative to

landmarks (including tracheal branches) visible on the anterior surface of the brain. The bottom of the central tracheal branch, directly below the medial ocellus, indicated the position of the CX. Yellow dashed line indicates brain midline and small yellow line with $\mathrm{L}$ (lesion on left) and $\mathrm{R}$ (lesion on right) show lesion locations.

(B) Confocal scan of an anti-synapsin labelled wood ant brain. CX is marked with a yellow rectangle. (C) The experimental arena in which naïve ants were recorded. Circular white platform (radius: $60 \mathrm{~cm}$ ) is located in the centre of a cylinder (radius: $1.5 \mathrm{~m}$, height: $1.8 \mathrm{~m}$ ). A $20^{\circ}$ wide black rectangle (height: $90 \mathrm{~cm}$, width: $52 \mathrm{~cm}$ ) is mounted at the inner wall of the surrounding cylinder. A camera recorded the ants' paths from above. A small door permitted access to the arena shown here open and larger for clarity. 

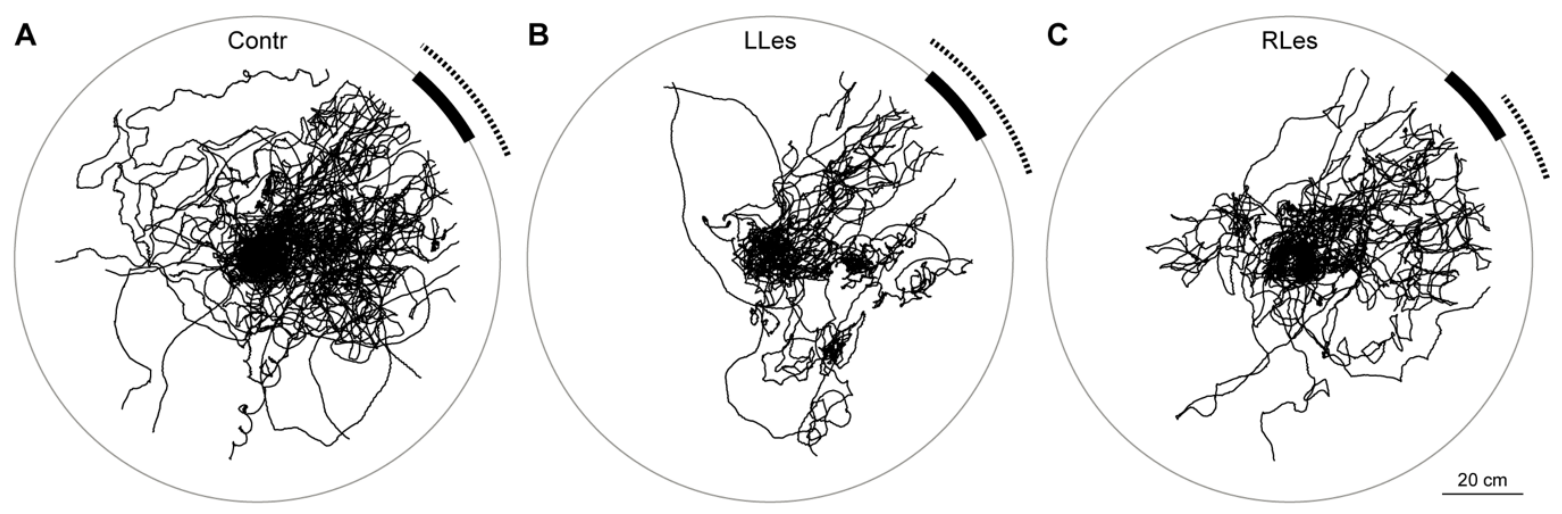

Figure 2

184

185

186

187

188

189

190

191

192

193

194

195

196

197

198

199

200

201

Figure 2: Innate visual attraction in wood ants is not affected by lesions in the CX. (A) Paths of control ants released at the centre of the arena are shown as black lines. Dotted arcs show 95\% confidence intervals (CIs) of the heading directions. The visual cue is shown at the platform edge instead of on the cylinder wall. (B) As for A but for ants with lesions on the left side of the CX. (C) As in A but for ants with lesions on the right side of the CX. For sample sizes see Results.
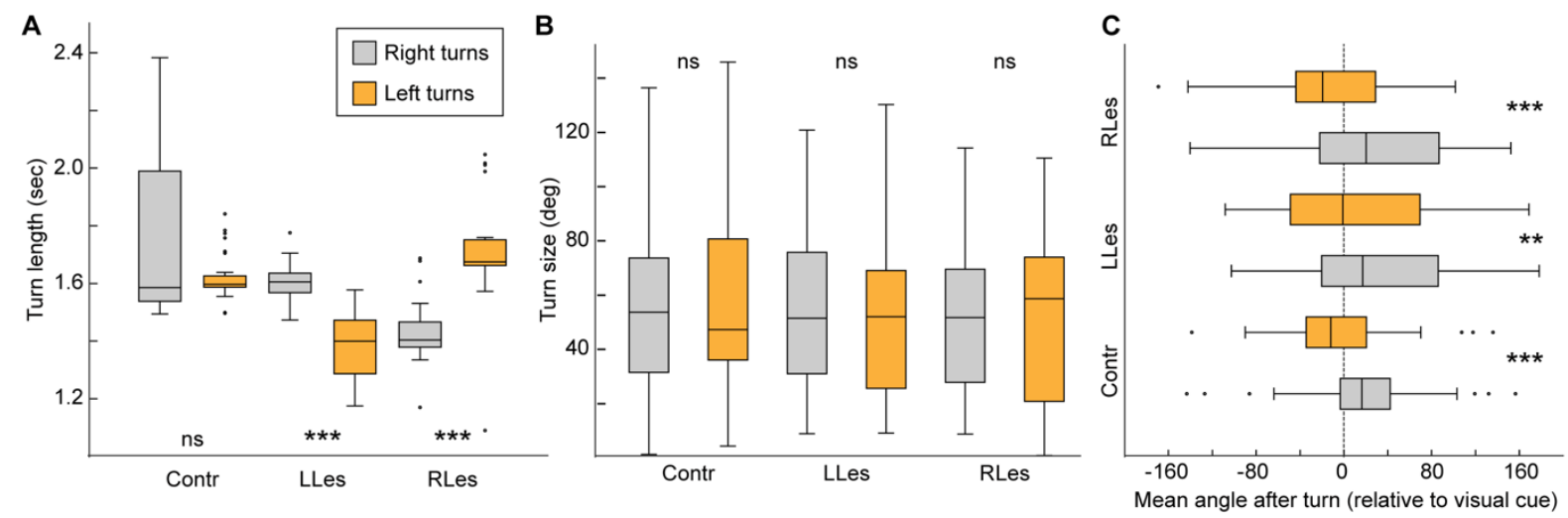

Figure 3

Figure 3: Lesions in the CX disrupt turning. (A) Control ants spent on average an equal amount of time turning to the left and right, whereas lesioned ants spent less time turning to the ipsilateral side of the lesion, i.e. right lesion ants spent less time turning to the right whereas left lesion ants spent less time turning to the left. Here and in the following panels, an average value from every ant is taken. (B) Size of turns did not differ between left and right turns in all three groups. (C) Angles at the end of the turns differed in all three groups between left and right turns, however, end points after both the left and right turns respectively did not differ between the three groups. Boxplots: median, 25th and 75th percentiles (edges of the boxes) and whiskers for extreme values not considered as outliers (circles). Wilcoxon tests: $\mathrm{ns}$, not significant; ${ }^{* *}, \mathrm{p}<0.01 ; * * *, \mathrm{p}<0.001$. For further statistics and sample sizes see Results. 


\section{REFERENCES}

204

205

206

207

208

209

210

211

212

213

214

215

216

217

1. Bausenwein, B., Mueller, N.R. \& Heisenberg, M. (1994). Behavior-dependent activity labeling in the central complex of Drosophila during controlled visual stimulation. J. Comp. Neurol., 340, 255268.

2. Bender, J.A., Pollack, A.J. \& Ritzmann, R.E. (2010). Neural Activity in the Central Complex of the Insect Brain Is Linked to Locomotor Changes. Curr. Biol., 20, 921-926.

3. Buehlmann, C., Aussel, A. \& Graham, P. (2020a). Dynamic multimodal interactions in navigating wood ants: What do path details tell us about cue integration? J. Exp. Biol., 223, jeb221036.

4. BuehImann, C. \& Graham, P. (2021). Innate visual attraction in wood ants is a hardwired behaviour seen across different motivational and ecological contexts. bioRxiv, https://doi.org/10.1101/2021.1101.1129.428794.

5. Buehlmann, C., Graham, P., Hansson, B.S. \& Knaden, M. (2014). Desert ants locate food by combining high sensitivity to food odors with extensive crosswind runs. Curr. Biol., 24, 960964.

6. Buehlmann, C., Mangan, M. \& Graham, P. (2020b). Multimodal interactions in insect navigation. Anim. Cogn., 23, 1129-1141.

7. Buehlmann, C., Wozniak, B., Goulard, R., Webb, B., Graham, P. \& Niven, J. (2020c). Mushroom bodies are required for learnt visual navigation but not for innate visual behaviour in ants. Curr. Biol., 30, 3438-3443.

8. Collett, M. (2010). How desert ants use a visual landmark for guidance along a habitual route. Proc. Natl. Acad. Sci. U. S. A., 107, 11638-11643.

9. Collett, M., Chittka, L. \& Collett, T. (2013). Spatial Memory in Insect Navigation. Curr. Biol., 23, R789R800.

10. Collett, T. (1988). How ladybirds approach nearby stalks: a study of visual selectivity and attention. J. Comp. Physiol. A, 163, 355-363.

11. Collett, T.S., Collett, M. \& Wehner, R. (2001). The guidance of desert ants by extended landmarks. J. Exp. Biol., 204, 1635-1639.

12. Collett, T.S., Lent, D.D. \& Graham, P. (2014). Scene perception and the visual control of travel direction in navigating wood ants. Philos. Trans. R. Soc. B, 369, 20130035.

13. Dewar, A.D.M., Wystrach, A., Philippides, A. \& Graham, P. (2017). Neural coding in the visual system of Drosophila melanogaster: How do small neural populations support visually guided behaviours? PLoS Comp. Biol., 13, e1005735.

14. el Jundi, B., Warrant, E.J., Byrne, M.J., Khaldy, L., Baird, E., Smolka, J. et al. (2015). Neural coding underlying the cue preference for celestial orientation. Proc. Natl. Acad. Sci. U. S. A., 112, 11395-11400.

15. Gotz, K.G. (1987). Course-control, metabolism and wing interference during ultralong tethered flight in Drosophila melanogaster. J. Exp. Biol., 128, 35-46.

16. Graham, P., Fauria, K. \& Collett, T.S. (2003). The influence of beacon-aiming on the routes of wood ants. J. Exp. Biol., 206, 535-541. 
17. Graham, P. \& Philippides, A. (2017). Vision for navigation: What can we learn from ants? Arthropod Structure \& Development, 46, 718-722.

18. Grob, R., Fleischmann, P.N., Grubel, K., Wehner, R. \& Roessler, W. (2017). The Role of Celestial Compass Information in Cataglyphis Ants during Learning Walks and for Neuroplasticity in the Central Complex and Mushroom Bodies. Front. Behav. Neurosci., 11.

19. Guo, P.Y. \& Ritzmann, R.E. (2013). Neural activity in the central complex of the cockroach brain is linked to turning behaviors. J. Exp. Biol., 216, 992-1002.

20. Harrison, J.F., Fewell, J.H., Stiller, T.M. \& Breed, M.D. (1989). Effects of experience on use of orientation cues in the giant tropical ant. Anim. Behav., 37, 869-871.

21. Heinze, S. (2017). Unraveling the neural basis of insect navigation. Curr. Opin. Insect. Sci., 24, 5867.

22. Heinze, S., Florman, J., Asokaraj, S., el Jundi, B. \& Reppert, S.M. (2013). Anatomical basis of sun compass navigation II: The neuronal composition of the central complex of the monarch butterfly. J. Comp. Neurol., 521, 267-298.

23. Heinze, S. \& Reppert, S.M. (2011). Sun compass integration of skylight cues in migratory monarch butterflies. Neuron, 69, 345-358.

24. Heusser, D. \& Wehner, R. (2002). The visual centring response in desert ants, Cataglyphis fortis. J. Exp. Biol., 205, 585-590.

25. Honkanen, A., Adden, A., Freitas, J.D. \& Heinze, S. (2019). The insect central complex and the neural basis of navigational strategies. J. Exp. Biol., 222, jeb188854.

26. Knaden, M. \& Graham, P. (2016). The Sensory Ecology of Ant Navigation: From Natural Environments to Neural Mechanisms. Annu. Rev. Entomol., 61, 63-76.

27. Kuntz, S., Poeck, B., Sokolowski, M.B. \& Strauss, R. (2012). The visual orientation memory of Drosophila requires Foraging (PKG) upstream of Ignorant (RSK2) in ring neurons of the central complex. Learn. Memory, 19, 337-340.

28. Lent, D.D., Graham, P. \& Collett, T.S. (2010). Image-matching during ant navigation occurs through saccade-like body turns controlled by learned visual features. Proc. Natl. Acad. Sci. U. S. A., $107,16348-16353$.

29. Liu, G., Seiler, H., Wen, A., Zars, T., Ito, K., Wolf, R. et al. (2006). Distinct memory traces for two visual features in the Drosophila brain. Nature, 439, 551-556.

30. Martin, J.P., Guo, P., Mu, L., Harley, C.M. \& Ritzmann, R.E. (2015). Central-Complex Control of Movement in the Freely Walking Cockroach. Curr. Biol., 25, 2795-2803.

31. Mueller, M. \& Wehner, R. (2010). Path Integration Provides a Scaffold for Landmark Learning in Desert Ants. Curr. Biol., 20, 1368-1371.

32. Neuser, K., Triphan, T., Mronz, M., Poeck, B. \& Strauss, R. (2008). Analysis of a spatial orientation memory in Drosophila. Nature, 453, 1244-1247.

33. Ofstad, T.A., Zuker, C.S. \& Reiser, M.B. (2011). Visual place learning in Drosophila melanogaster. Nature, 474, 204-207.

34. Pegel, U., Pfeiffer, K. \& Homberg, U. (2018). Integration of celestial compass cues in the central complex of the locust brain. J. Exp. Biol., 221, jeb171207. 
35. Pfeiffer, K. \& Homberg, U. (2014). Organization and Functional Roles of the Central Complex in the Insect Brain. Annu. Rev. Entomol., 59, 165-184.

36. Poteser, M. \& Kral, K. (1995). Visual distance discrimination between stationary targets in praying mantids: an index of the use of motion parallax. J. Exp. Biol., 189, 2127-2137.

37. Ridgel, A.L., Alexander, B.E. \& Ritzmann, R.E. (2007). Descending control of turning behavior in the cockroach, Blaberus discoidalis. J. Comp. Physiol. A, 193, 385-402.

38. Ritzmann, R.E., Ridgel, A.L. \& Pollack, A.J. (2008). Multi-unit recording of antennal mechanosensitive units in the central complex of the cockroach, Blaberus discoidalis. J. Comp. Physiol. A, 194, 341-360.

39. Rosner, R. \& Homberg, U. (2013). Widespread Sensitivity to Looming Stimuli and Small Moving Objects in the Central Complex of an Insect Brain. J. Neurosci., 33, 8122-8133.

40. Sakura, M., Lambrinos, D. \& Labhart, T. (2008). Polarized skylight navigation in insects: model and electrophysiology of e-vector coding by neurons in the central complex. J. Neurophysiol., 99, 667-682.

41. Seelig, J.D. \& Jayaraman, V. (2013). Feature detection and orientation tuning in the Drosophila central complex. Nature, 503, 262-266.

42. Seelig, J.D. \& Jayaraman, V. (2015). Neural dynamics for landmark orientation and angular path integration. Nature, 521, 186-191.

43. Steinbeck, F., Adden, A. \& Graham, P. (2020). Conecting brain to behaviour: a rol for general purpose steering circuits in insect orientation? J. Exp. Biol., 223, jeb212332.

44. Stone, T., Webb, B., Adden, A., Ben Weddig, N., Honkanen, A., Templin, R. et al. (2017). An Anatomically Constrained Model for Path Integration in the Bee Brain. Curr. Biol., 27, 30693085 .

45. Strausfeld, N.J. (1999). A brain region in insects that supervises walking. Prog. Brain Res., 123, 273284.

46. Strauss, R. \& Pichler, J. (1998). Persistence of orientation toward a temporarily invisible landmark in Drosophila melanogaster. J. Comp. Physiol. A, 182, 411-423.

47. Turner-Evans, D.B. \& Jayaraman, V. (2016). The insect central complex. Curr. Biol., 26, R453-R457.

48. Varga, A.G., Kathman, N.D., Martin, J.P., Guo, P.Y. \& Ritzmann, R.E. (2017). Spatial Navigation and the Central Complex: Sensory Acquisition, Orientation, and Motor Control. Front. Behav. Neurosci., 11.

49. Vitzthum, H., Muller, M. \& Homberg, U. (2002). Neurons of the central complex of the locust Schistocerca gregaria are sensitive to polarized light. J. Neurosci., 22, 1114-1125.

50. Voss, C. (1967). Uber das Formensehen der roten Waldameise (Formica rufa Gruppe). Zeitschrift Fur Vergleichende Physiologie, 55, 225-254.

51. Wallace, G.K. (1962). Experiments on visually controlled orientation in the desert locust, Schistocerca gregaria (Forskål). Anim. Behav., 10, 361-369

52. Webb, B. \& Wystrach, A. (2016). Neural mechanisms of insect navigation. Curr. Opin. Insect. Sci., 15, 27-39. 
53. Wehner, R. (1972). Spontaneous pattern preferences of Drosophila melanogaster to black areas in various parts of the visual field. J. Insect Physiol., 18, 1531-1543.

324 54. Wehner, R., Cheng, K. \& Cruse, H. (2014). Visual Navigation Strategies in Insects: Lessons from Desert Ants. MA: MIT Press, Cambridge.

326 55. Zeil, J. (2012). Visual homing: an insect perspective. Curr. Opin. Neurobiol., 22, 285-293. 